\title{
Construction of health risk assessment index system for assessing the risk of chronic diseases based on the concept of massive health
}

\author{
Ran Hao \\ Hebei Medical University \\ Meng Zhang \\ Hebei Medical University \\ Nan Zhao \\ Hebei Medical University \\ Peng Zhang \\ Hebei Medical University

\section{Rumeng Zhao} \\ Hebei Medical University \\ Jie Hu ( $\sim$ huj3993@sina.com )
}

\section{Research article}

Keywords: Chronic diseases, Health risk assessment, Index system, Family doctors, Massive health

Posted Date: January 10th, 2020

DOI: https://doi.org/10.21203/rs.2.20568/v1

License: (9) This work is licensed under a Creative Commons Attribution 4.0 International License. Read Full License 


\section{Abstract}

Background: Massive health, a national strategy in China, calls for maintaining people's health in an allround way. This puts forward a new challenge for family doctors (FDs) to improve the ability of chronic diseases management. As the main service force in the community, FDs need to change the service concept and improve their management level of chronic diseases. In the background of massive health, we aimed to construct the health risk assessment index system (HRAIS), with the hope of helping FDs to carry out chronic disease management, especially to identify and monitor main chronic diseases and their risk factors in the community.

Methods : Available health indexes, national health databases and chronic disease surveillance systems were reviewed to identify potential indexes and evaluation methods of the indexes. Delphi method was performed to establish the HRAIS, and the analytic hierarchy process was used to calculate the indexes weight.

Results : The final HRAIS included 4 first-level indexes and 38 second-level indexes. We also determined the evaluation methods for the 38 indexes. The authority coefficient was 0.86 . The Kendall's $W$ for the two rounds of Delphi consultation were 0.202 and 0.210 , respectively $(p<0.001)$. The weights of the first-level indexes from high to low were physiological health (0.4094), psychosocial health (0.2895), health-related behaviors (0.2047) and environment (0.0965).

Conclusion : The HRAIS is a multi-dimension and multi-index tool, which can be used as a guideline for FDs in early screening, early intervention and classified management of main chronic diseases. Keywords : Chronic diseases, Health risk assessment, Index system, Family doctors, Massive health

\section{Background}

Health is a key element to a prosperous society. In the National Conference on Sanitation and Health in China, General Secretary Xi Jinping put forward the concept of massive health for the first time, which emphasized that the whole society must establish the awareness of the comprehensive health, including physical, psychological, environmental, and moral health and health in social adaptation [1]. Massive health is a comprehensive development concept proposed in line with the development of history, reflecting the country's concern for people's health. Currently, main chronic diseases including cardiovascular disease, cancer, diabetes and chronic respiratory diseases constitute serious threats to human health [2]. Simultaneously, China's "Medium to Long Term Plan for the Prevention and Treatment of Chronic Diseases (2017-2025)" clearly stated that chronic diseases had become a major public health problem, threatening the health of Chinese residents [3]. Moreover, with the increasing aging population, the impact of chronic diseases on people's health and social economy will further expand [4]. How to deal with the threat of main chronic diseases is an urgent problem in medical and health work in China.

Community health management is an effective means to prevent and control chronic diseases, but its development in China is still facing a lot of difficulties. At present, community health management still 
focused on the disease management, and there is a lack of continuous and comprehensive health management. In addition, the uneven distribution of health resources, the low trust of residents in community medical institutions, and the imperfection of relevant policies also seriously restrict the development of community health management in China [5]. In recent years, the establishment of family doctor contract services system is of great significance to the development of community health management. Family doctor contract services is essentially the extension and development of community health services based on the services for general practitioners. By signing the contract, the contracted residents are provided with continuous and comprehensive health accountability management [6]. In 2016, the State Council Medical Reform Office released the "Guiding Opinions on Promoting Family Doctor Contract Services", which clearly pointed out that it was necessary to accelerate the development of family doctor contract services in China [7]. Practice has proved that family doctors (FDs) could fulfill the gatekeeper duty and play an important role in the prevention and control of chronic diseases $[8,9]$. However, residents show great reluctance to sign with FDs. One major reason is that contract services lack appeal to residents [10]. Therefore, with the development of family doctor contract services, more services should be provided to meet the growing health needs of residents.

Health management is an important part of family doctor contract services, and it is based on health risk assessment. Conducting personalized health risk assessment can enrich contract services and improve service levels. In China, FDs mainly use health records for disease monitoring and health assessment. However, there still exist some problems in health records in China. For example, some records are either incomplete or untrue or nonstandard. Especially, there is lack of data on risk factors related to chronic diseases [11, 12]. Therefore, FDs lack a standardized assessment tool to monitor and evaluate the risk factors of chronic diseases, and it's difficult for them to develop personalized diagnosis and treatment plans for patients [12].

Although health risk assessment in foreign countries has been gradually improved, due to racial and geographical differences, the direct use of foreign research results may lead to large deviations in China. Therefore, this study aimed to construct a standardized health risk assessment index system (HRAIS) under the guidance of massive health, so as to provide a guideline for FDs to monitor and evaluate the risk factors related to chronic diseases. On the one hand, personalized health risk assessment can enrich the service content and improve the service level of contracted services. On the other hand, it can provide the evidence for early screening, early intervention and classified management of main chronic diseases among contracted residents.

\section{Methods}

A health risk assessment instrument for chronic diseases should reflect the health condition and risk factors, emphasize functional indexes, and provide measures to prevent and control chronic diseases. In order to construct such a health risk assessment instrument, we undertook a literature review, and sought expert consultations. The Delphi method and the analytical hierarchy process (AHP) method were used. The flowchart of study process is shown in Fig. 1. 
The available resources, including national health indexes, national health databases and chronic disease surveillance systems, were reviewed to identify the potential indexes. Those indexes useful for public health action were included. Meanwhile, we searched PubMed, MEDLINE and China National Knowledge Infrastructure databases for eligible studies published from May 2010 to March 2019. Search terms included "chronic noncommunicable disease", "chronic disease", "health indexes", "family doctor contract services", "health assessment" and "health risk assessment". The index selection criteria were as follows: 1) the index was directly relevant to chronic diseases prevention and control; 2) the index measuring and data collecting should be convenient and feasible; 3 ) the index must be consistent with the prioritized areas and priorities of government work.

As a global health development concept, massive health requires health workers to "provide full-cycle health services in an all-round way for people" [1]. Based on this concept, we designed a framework of four first-level indexes. The four first-level indexes were physiological health, psychosocial health, healthrelated behaviors and environment.

\section{Delphi consultation process}

We performed the Delphi method and collected the experts' opinions and suggestions for the index system [13]. To begin with, through literature review, we established an index list, based on which a questionnaire was worked out for expert consultation. Experts were asked to appraise each index according to the questionnaire, which included three parts: instructions, text content and general information of experts. The instructions described the purpose and background of this study. The text content included the scoring system for index importance and their evaluation methods. The degree of index importance was evaluated by experts using a five-point Likert rating scale ( 5 points, very important; 4 points, important; 3 points, moderately important; 2 points, of little importance; 1 point, unimportant). There was a comment bar in the questionnaire so that experts could provide their suggestions. The general information of experts consisted of work experience, education, professional title, judgment criteria, the degree of their familiarity with indexes, etc.

Then, we determined the indexes and their evaluation methods through Delphi method. We performed two rounds of expert consultations by sending email to each expert from May to July 2019. The number of the experts were decided based on the following two reasons: 1) In Delphi study, the number of experts is not clearly regulated and it is usually determined by the purpose of the study and available resources $[14,15]$. 2) Studies have shown that 10 to 18 experts can ensure adequate contributions $[15,16]$. Therefore, we invited 15 experts as consultants from medical colleges, centers for disease control and prevention, and medical institutions. The selection criteria for experts were: 1) they should be familiar with the connotation of family doctor contract services; 2 ) they should be engaged in the fields related to chronic diseases; 3 ) they should at least possess an intermediate professional title; 4) they should be interested in this study or active in supporting it. 
We calculated the mean, standard deviation (SD) and coefficient of variation (CV) for each index. These indexes were screened and modified based on experts' opinions and consensus on the importance of the index, and the index was removed if its CV was $\geq 0.3$ [17]. The modified indexes after the first-round consultation were sent to the experts along with the second-round questionnaire. The Delphi consultation was finished if the experts' authority coefficient $(\mathrm{Cr})$ and the Kendall coefficient of concordance (or Kendall's W) met all the requirements. Cr represented the authority of experts, which was expressed by the mean of the familiarity degree coefficient (Cs) and the judgment basis coefficient (Ca). The formula for the expert authority coefficient was: $\mathrm{Cr}=(\mathrm{Ca}+\mathrm{CS}) / 2 . \mathrm{Cr} \geq 0.7$ indicated a high degree of authority among experts. The Kendall's W was used to evaluate the concordance of the responses of experts, and $p$ value less than 0.05 was considered significant. In the Delphi stage, SPSS 20.0 (IBM, Armonk, New York, USA) was used for the statistical analysis.

\section{AHP method}

We adopted the analytical hierarchy process (AHP) to determine the weight for each index [18]. First of all, based on the results of the second round of Delphi consultation, the hierarchical structure model was constructed. Then, pairwise comparisons were performed to calculate the relative value of each index and to draw a judgment matrix. The evaluation criteria shown in Table 1 were used in the comparison. In calculating the weights, the elements of each column in a consistent paired comparison matrix were processed through normalization. Finally, the logic of judgment was checked by calculating the consistency of judgment matrix. The eigenvalue method proposed by Saaty was used to evaluate the weight [19]. Generally, if the random consistency ratio (CR) was less than 0.1 , the judgment matrix was regarded as consistent, and the weight coefficient was thought to meet logic consistency. The results were analyzed using YAAHP software.

Table 1 Pairwise comparison scale of indexes in the AHP

\begin{tabular}{|lll|}
\hline Mark & Description & Explanation \\
\hline 1 & Equal importance & The indexes made the same contribution to the goal. \\
\hline 3 & Slight importance & $\begin{array}{l}\text { This index was slightly better than another index based on } \\
\text { experience. }\end{array}$ \\
\hline 5 & Basic importance & $\begin{array}{l}\text { This index was better than another index based on the } \\
\text { experience. }\end{array}$ \\
\hline 9 & Strong importance & $\begin{array}{l}\text { This index was much more important than another index } \\
\text { based on the experience. }\end{array}$ \\
\hline $\begin{array}{l}(2,4, \\
6,8)\end{array}$ & $\begin{array}{l}\text { Intermediate values of two } \\
\text { adjacent levels }\end{array}$ & $\begin{array}{l}\text { The degree of importance for this index was very obvious. } \\
\text { Intermediate values were used to represent comparisons. }\end{array}$ \\
\hline
\end{tabular}




\section{Development of a framework for index system}

Under the guidance of massive health, FDs should not only reinforce the prevention and treatment of diseases, but also pay attention to maintaining and restoring the functional condition of patients so that the life quality of patients can be improved. As a tool for FDs to monitor and assess the risk of chronic diseases, the HRAIS should fully reflect residents' health condition and their risk factors associated with chronic diseases. Therefore, we established an index system including four first-level indexes:

physiological health, psychosocial health, health-related behaviors and environment. After that, we used WHO stepwise monitoring to evaluate chronic diseases and their risk factors. We collected the data of the risk factors related to chronic diseases through questionnaire survey, physical measurement and biochemical detection. In particular, our data collection was based on the principle of choosing mature and effective measurement tools at home and abroad, in line with China's national conditions. Due to the fact that there were no recognized questionnaires for certain indexes, data collection was based on selfreports of contracted residents. Finally, on the basis of the established index system, we have preliminarily determined the index evaluation method. Through literature reviews, we selected a total of 42 relevant indexes including evaluation methods, and initially developed a framework for the index system.

\section{Delphi expert consultation}

This study consulted 15 experts from medical colleges, medical institutions and centers for disease control and prevention. Of the experts, $93.3 \%$ hold senior professional titles. The mean age of them was $50.6 \pm 7.7$ (range: $35-66$ ) years; mean working duration was $22.5 \pm 8.1$ (range: $3-33$ ) years. The experts discussed the significance and feasibility of 42 indexes, as well as the evaluation methods. At the end of the expert consultation, the recovery rate of the two rounds of questionnaires was $100 \%$.

Based on the experts' self-assessment scores, the expert authority coefficient of Delphi was 0.86 (CS for 0.825 , CA for 0.89 ). It showed that the experts were familiar with these indexes. The value of Kendall's $W$ represented the degree of expert concordance. In this study, the Kendall's W values of the two rounds were 0.202 and 0.210 (Table 2), indicating that the degree of concordance among the experts was acceptable.

Table 2 The results of experts' opinions coordination degree

\begin{tabular}{|l|llll|}
\hline \multicolumn{4}{|c|}{ Index importance } \\
\cline { 2 - 4 } & Kendall's W & Chi square value & p-Value \\
& First round & 0.202 & 136.373 & $<0.001$ \\
Second round & 0.210 & 135.424 & $<0.001$ \\
\cline { 2 - 4 }
\end{tabular}


In the first round of Delphi consultation, a total of 42 indexes were assessed. The mean score of the importance of these indexes ranged from 3.60 to 4.73 , and the $C V$ ranged from 0.1 to 0.33 (Table 3). Based on the index screening principle and experts' advice, we removed body temperature, skin and residential floor. We also deleted the light environment since the connotation and measurement were difficult to define. However, we added mental stress and psychological stress, because they could affect human health to some extent. Additionally, the daily life activity ability and gait and balance ability were used to assess balance function and self-care ability. According to the experts' advice, we categorized these two indexes into the dimension of health-related behaviors. Acting on the experts' opinion, we revised the assessment method of the occupational exposure. After the panel discussion, we determined the occupational risks by assessing high-risk occupation protection criteria in residents' self-reports. As a result, 40 indexes and their evaluation methods were retained in the second round. 
Table 3

Results of two rounds of expert consultation

\begin{tabular}{|c|c|c|c|c|c|c|}
\hline \multirow{3}{*}{ Index } & \multicolumn{6}{|c|}{ Index importance } \\
\hline & \multicolumn{3}{|c|}{ First round } & \multicolumn{3}{|c|}{ Second round } \\
\hline & Mean & SD & CV & Mean & SD & $\mathrm{CV}$ \\
\hline A Physiological health & 4.73 & 0.46 & 0.10 & 4.86 & 0.50 & 0.10 \\
\hline B Psychosocial health & 4.60 & 0.63 & 0.14 & 4.80 & 0.40 & 0.08 \\
\hline C Health-related behaviors & 4.60 & 0.63 & 0.14 & 4.73 & 0.68 & 0.14 \\
\hline D Environment & 4.00 & 0.85 & 0.21 & 4.47 & 0.72 & 0.16 \\
\hline A1Body temperature ${ }^{a}$ & 4.00 & 1.20 & 0.30 & - & - & - \\
\hline A2 Pulse & 4.27 & 0.80 & 0.19 & 4.66 & 0.60 & 0.13 \\
\hline A3 Respiration & 4.20 & 0.94 & 0.22 & 4.53 & 0.62 & 0.14 \\
\hline A4 Blood Pressure & 4.73 & 0.46 & 0.10 & 4.80 & 0.54 & 0.11 \\
\hline A5 Pain & 4.47 & 0.64 & 0.14 & 4.47 & 0.62 & 0.14 \\
\hline A6 Heart rate & 4.47 & 0.64 & 0.14 & 4.67 & 0.60 & 0.13 \\
\hline A7 Vital capacity & 4.00 & 1.07 & 0.27 & 4.07 & 1.12 & 0.28 \\
\hline A8 BMI & 4.60 & 0.63 & 0.14 & 4.40 & 0.80 & 0.18 \\
\hline A9 Waist & 4.47 & 0.64 & 0.14 & 4.13 & 0.72 & 0.17 \\
\hline A10 Hip circumference & 4.33 & 0.72 & 0.17 & 3.87 & 0.88 & 0.23 \\
\hline A11 Defecation & 4.20 & 1.01 & 0.24 & 4.40 & 0.61 & 0.14 \\
\hline A12 Glycated hemoglobin & 4.60 & 0.51 & 0.11 & 4.60 & 0.61 & 0.13 \\
\hline A13 Blood sugar & 4.73 & 0.46 & 0.10 & 4.73 & 0.57 & 0.12 \\
\hline A14 Hyperuricemia & 4.40 & 0.51 & 0.12 & 4.47 & 0.72 & 0.16 \\
\hline A15 Homocysteine & 4.40 & 0.63 & 0.14 & 4.40 & 0.71 & 0.16 \\
\hline A16 Blood lipid & 4.67 & 0.49 & 0.10 & 4.60 & 0.61 & 0.13 \\
\hline A17 Serum calcium & 4.13 & 0.83 & 0.20 & 4.13 & 0.72 & 0.17 \\
\hline
\end{tabular}

SD, standard deviation; CV, coefficient of variation;

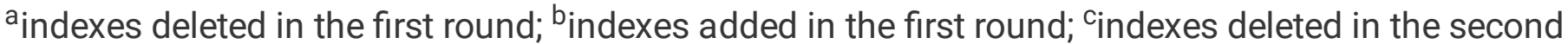
round. 


\section{Index importance}

\begin{tabular}{|c|c|c|c|c|c|c|}
\hline A18 Red blood cell count & 4.13 & 0.83 & 0.20 & 4.13 & 0.88 & 0.21 \\
\hline A19 White blood cell count & 4.00 & 0.93 & 0.23 & 4.07 & 0.93 & 0.23 \\
\hline A20 Bone density & 4.33 & 0.82 & 0.19 & 4.07 & 0.85 & 0.21 \\
\hline A21 Skin ${ }^{a}$ & 3.73 & 1.22 & 0.33 & - & - & - \\
\hline A22 Eyesight & 4.47 & 0.64 & 0.14 & 4.07 & 0.85 & 0.21 \\
\hline B1 Cognition & 4.67 & 0.82 & 0.18 & 4.80 & 0.40 & 0.08 \\
\hline B2 Depression & 4.53 & 0.83 & 0.18 & 4.67 & 0.47 & 0.10 \\
\hline B3 Anxiety & 4.53 & 0.83 & 0.18 & 4.67 & 0.47 & 0.10 \\
\hline B4 Life events & 4.40 & 0.99 & 0.23 & 4.60 & 0.49 & 0.11 \\
\hline B5 Social support & 4.47 & 0.74 & 0.17 & 4.67 & 0.47 & 0.10 \\
\hline B6 Mental stress ${ }^{b, c}$ & - & - & - & 4.67 & 0.47 & 0.10 \\
\hline B7 Psychological stress ${ }^{b}$ & - & - & - & 4.67 & 0.47 & 0.10 \\
\hline C1 Physical activity & 4.40 & 0.74 & 0.17 & 4.47 & 0.62 & 0.14 \\
\hline C2 Dietary nutrition & 4.53 & 0.52 & 0.11 & 4.53 & 0.62 & 0.14 \\
\hline C3 Alcohol drinking & 4.53 & 0.52 & 0.11 & 4.73 & 0.57 & 0.12 \\
\hline C4 Smoking & 4.53 & 0.52 & 0.11 & 4.73 & 0.57 & 0.12 \\
\hline C5 Sleep and rest & 4.47 & 0.64 & 0.14 & 4.67 & 0.60 & 0.13 \\
\hline C6 Medication safety & 4.73 & 0.46 & 0.10 & 4.73 & 0.57 & 0.12 \\
\hline C7 Gait and balance & 4.47 & 0.83 & 0.19 & 4.40 & 0.61 & 0.14 \\
\hline C8 Activities of daily living & 4.60 & 0.83 & 0.19 & 4.67 & 0.60 & 0.13 \\
\hline D1 Residence type ${ }^{c}$ & 3.67 & 0.98 & 0.27 & 4.00 & 0.89 & 0.22 \\
\hline D2 Residential floor ${ }^{a}$ & 3.60 & 1.12 & 0.31 & - & - & - \\
\hline D3Acoustic environment & 3.93 & 0.88 & 0.22 & 4.40 & 0.61 & 0.14 \\
\hline D4 Light environment ${ }^{a}$ & 3.93 & 0.88 & 0.22 & - & - & - \\
\hline
\end{tabular}

$\mathrm{SD}$, standard deviation; $\mathrm{CV}$, coefficient of variation;

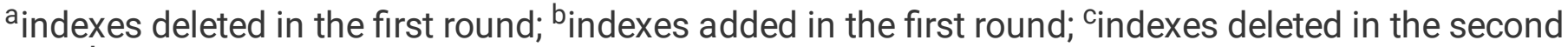
round. 


\section{Index importance}

\begin{tabular}{|lllllll}
\hline D5 Indoor air environment & 3.87 & 0.83 & 0.21 & 4.33 & 0.70 & 0.16 \\
\hline D6 Occupational Exposure & 3.93 & 1.03 & 0.26 & 4.40 & 0.71 & 0.16 \\
\hline D7 Medical security & 4.27 & 0.88 & 0.20 & 4.47 & 0.62 & 0.14
\end{tabular}

SD, standard deviation; CV, coefficient of variation;

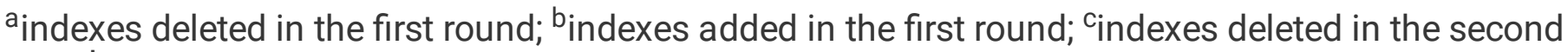
round.

In the second round of Delphi consultation, the mean score of the index importance ranged from 3.87 to 4.86, and the CV ranged from 0.08 to 0.28 (Table 3). Based on the results of the current round of consultation, we deleted the residence types. The reason was that there were not enough empirical studies on residence types and it was difficult to standardize the description of the evaluation criteria. We also combined the mental stress and psychological stress into the subjective stress, and used Perceived Stress Scale to measure it. We modified the evaluation method of medication safety according to the experts' suggestions. The medication safety was evaluated from four aspects: medication types, storage methods, side effects and medication adherence. The HRAIS was established after the second round of Delphi consultation. It comprised of 38 indexes and their evaluation methods (Table 3 ).

\section{AHP results}

Based on the results of two rounds of Delphi consultation, we performed AHP to check the consistency of HRAIS and determine the weight of each index. According to the results of consistency test, the CR values of the first-level indexes and second-level indexes were both less than 0.1 , indicating that the judgment matrix met the consistency requirement. In the order of weights from high to low, the four first-level indexes were physiological health (0.4094), psychosocial health $(0.2895)$, health-related behaviors (0.2047) and environment (0.0965). The weight for each index was listed in Table 4. Within physiological health, blood pressure (0.0455), blood glucose (0.0414), heart rate (0.0352), glycated hemoglobin (0.0272) and blood lipid (0.0272) accounted for a large proportion. Within psychosocial health, the weight coefficients of secondary indexes from high to low were cognition (0.0821), depression (0.0453), anxiety (0.0453), social support (0.0511), psychological stress $(0.0290)$ and life events $(0.0290)$. Within healthrelated behaviors, smoking (0.0387), alcohol drinking $(0.0387)$ and medication safety $(0.0387)$ had a greater weight. Within environmental, medical insurance $(0.0381)$ had the greatest weight. 
Table 4

Final indexes and weight of each index

\begin{tabular}{|c|c|c|c|}
\hline $\begin{array}{l}\text { First-level } \\
\text { index and } \\
\text { weight }\end{array}$ & $\begin{array}{l}\text { Second-level } \\
\text { index }\end{array}$ & Assessment method or content & Weight \\
\hline \multirow{12}{*}{$\begin{array}{l}\text { Physiological } \\
\text { health } \\
(0.4094)\end{array}$} & Pulse & Physical examination & 0.0352 \\
\hline & Respiration & Physical examination & 0.0230 \\
\hline & $\begin{array}{l}\text { Blood } \\
\text { Pressure }\end{array}$ & Physical examination & 0.0455 \\
\hline & Pain & Numeric rating scale & 0.0202 \\
\hline & Heart rate & Physical examination & 0.0352 \\
\hline & Vital capacity & Physical examination & 0.0066 \\
\hline & BMI & $\mathrm{BMI}=$ weight $(\mathrm{kg}) /$ height $(\mathrm{m})^{2}$ & 0.0131 \\
\hline & $\begin{array}{l}\text { Waist } \\
\text { circumference }\end{array}$ & Physical examination & 0.0066 \\
\hline & $\begin{array}{l}\text { Hip } \\
\text { circumference }\end{array}$ & Physical examination & 0.0131 \\
\hline & Defecation & $\begin{array}{l}\text { Self-report whether you often find it difficult to defecate } \\
\text { or defecate less than three times a week }\end{array}$ & 0.0171 \\
\hline & $\begin{array}{l}\text { Glycated } \\
\text { hemoglobin }\end{array}$ & Laboratory examination & 0.0272 \\
\hline & Blood glucose & Laboratory examination & 0.0414 \\
\hline
\end{tabular}

Physical examination and laboratory examination refer to the examination items carried out by hospitals or physical examination centers, with or without clinical diagnostic significance as the evaluation criteria.

In the questionnaire survey, we preferred mature and effective measurement tools at home and abroad, which were expressed in bold text. For another part of the index, we used a self-designed questionnaire to describe the specific content of risk assessment.

aAlcohol drinking was assessed in four ways: (1) frequency of drinking, (2) alcohol consumed, (3) drinking types and (4) harmful drinking. Harmful drinking refers to the number of days in which men drank more than 5 standard drinking units at a single time in the past 12 months, and women drank more than 4 standard drinking units at a single time.

bSmoking was assessed in three ways: (1) daily smokers report the number of cigarettes smoked every day; other smokers report the average amount of smoking in a week, (2) the age when one started smoking and the age when one started smoking every day and (3) days of exposure to secondhand smoke per week. 


\begin{tabular}{|c|c|c|c|}
\hline \multirow[t]{9}{*}{$\begin{array}{l}\text { First-level } \\
\text { index and } \\
\text { weight }\end{array}$} & $\begin{array}{l}\text { Second-level } \\
\text { index }\end{array}$ & Assessment method or content & Weight \\
\hline & Hyperuricemia & Laboratory examination & 0.0202 \\
\hline & Homocysteine & Laboratory examination & 0.0171 \\
\hline & Blood lipid & Laboratory examination & 0.0272 \\
\hline & $\begin{array}{l}\text { Serum } \\
\text { calcium }\end{array}$ & Laboratory examination & 0.0097 \\
\hline & $\begin{array}{l}\text { Red blood cell } \\
\text { count }\end{array}$ & Laboratory examination & 0.0097 \\
\hline & $\begin{array}{l}\text { White blood } \\
\text { cell count }\end{array}$ & Laboratory examination & 0.0081 \\
\hline & Bone density & Laboratory examination & 0.0081 \\
\hline & Eyesight & Standard logarithmic visual acuity chart & 0.0081 \\
\hline \multirow{6}{*}{$\begin{array}{l}\text { Psychosocial } \\
\text { health } \\
(0.2895)\end{array}$} & Cognition & The Montreal Cognitive Assessment & 0.0832 \\
\hline & Depression & Self-rating depression scale & 0.0511 \\
\hline & Anxiety & Self-rating Anxiety Scale & 0.0511 \\
\hline & Life events & Life Event Scale & 0.0290 \\
\hline & Social support & Social support revalued scale & 0.0511 \\
\hline & $\begin{array}{l}\text { Psychological } \\
\text { stress }\end{array}$ & Perceived Stress Scale & 0.0290 \\
\hline
\end{tabular}

Physical examination and laboratory examination refer to the examination items carried out by hospitals or physical examination centers, with or without clinical diagnostic significance as the evaluation criteria.

In the questionnaire survey, we preferred mature and effective measurement tools at home and abroad, which were expressed in bold text. For another part of the index, we used a self-designed questionnaire to describe the specific content of risk assessment.

aAlcohol drinking was assessed in four ways: (1) frequency of drinking, (2) alcohol consumed, (3) drinking types and (4) harmful drinking. Harmful drinking refers to the number of days in which men drank more than 5 standard drinking units at a single time in the past 12 months, and women drank more than 4 standard drinking units at a single time.

bSmoking was assessed in three ways: (1) daily smokers report the number of cigarettes smoked every day; other smokers report the average amount of smoking in a week, (2) the age when one started smoking and the age when one started smoking every day and (3) days of exposure to secondhand smoke per week. 


\begin{tabular}{|c|c|c|c|}
\hline $\begin{array}{l}\text { First-level } \\
\text { index and } \\
\text { weight }\end{array}$ & $\begin{array}{l}\text { Second-level } \\
\text { index }\end{array}$ & Assessment method or content & Weight \\
\hline \multirow{8}{*}{$\begin{array}{l}\text { Health- } \\
\text { related } \\
\text { behaviors } \\
(0.2047)\end{array}$} & $\begin{array}{l}\text { Physical } \\
\text { activity }\end{array}$ & Chinese adult physical activity guidelines & 0.0131 \\
\hline & $\begin{array}{l}\text { Dietary } \\
\text { nutrition }\end{array}$ & Food frequency questionnaire & 0.0182 \\
\hline & $\begin{array}{l}\text { Alcohol } \\
\text { drinking }^{\mathrm{a}}\end{array}$ & $\begin{array}{l}\text { Self-reported behaviors of drinking types, drinking } \\
\text { frequency, drinking volume and harmful drinking }\end{array}$ & 0.0397 \\
\hline & Smoking ${ }^{b}$ & $\begin{array}{l}\text { Self-reported behaviors of smoking history, current } \\
\text { smoking status and passive smoking status }\end{array}$ & 0.0397 \\
\hline & Sleep and rest & Pittsburgh sleep quality index & 0.0247 \\
\hline & $\begin{array}{l}\text { Medication } \\
\text { safety }\end{array}$ & $\begin{array}{l}\text { Self-reported knowledge of medication types, storage, } \\
\text { side effects, and the behavior of medication compliance }\end{array}$ & 0.0397 \\
\hline & $\begin{array}{l}\text { Gait and } \\
\text { balance }\end{array}$ & Tinetti scale & 0.0100 \\
\hline & $\begin{array}{l}\text { Activities of } \\
\text { daily living }\end{array}$ & Activity of Daily Living Scale & 0.0247 \\
\hline \multirow[t]{3}{*}{$\begin{array}{l}\text { Environment } \\
(0.0965)\end{array}$} & $\begin{array}{l}\text { Acoustic } \\
\text { environment }\end{array}$ & Self-reported degree of noise disturbance & 0.0260 \\
\hline & $\begin{array}{l}\text { Indoor air } \\
\text { environment }\end{array}$ & $\begin{array}{l}\text { Self-reported status of room ventilation, household fuel } \\
\text { and kitchen smoke exhaust equipment }\end{array}$ & 0.0157 \\
\hline & $\begin{array}{l}\text { Occupational } \\
\text { exposure }\end{array}$ & $\begin{array}{l}\text { Self-report whether protective measures for high-risk } \\
\text { occupations are adequate }\end{array}$ & 0.0260 \\
\hline
\end{tabular}

Physical examination and laboratory examination refer to the examination items carried out by hospitals or physical examination centers, with or without clinical diagnostic significance as the evaluation criteria.

In the questionnaire survey, we preferred mature and effective measurement tools at home and abroad, which were expressed in bold text. For another part of the index, we used a self-designed questionnaire to describe the specific content of risk assessment.

aAlcohol drinking was assessed in four ways: (1) frequency of drinking, (2) alcohol consumed, (3) drinking types and (4) harmful drinking. Harmful drinking refers to the number of days in which men drank more than 5 standard drinking units at a single time in the past 12 months, and women drank more than 4 standard drinking units at a single time.

bSmoking was assessed in three ways: (1) daily smokers report the number of cigarettes smoked every day; other smokers report the average amount of smoking in a week, (2) the age when one started smoking and the age when one started smoking every day and (3) days of exposure to secondhand smoke per week. 


\begin{tabular}{llll|}
$\begin{array}{l}\text { First-level } \\
\text { index and } \\
\text { weight }\end{array}$ & $\begin{array}{l}\text { Second-level } \\
\text { index }\end{array}$ & Assessment method or content & Weight \\
\hline & $\begin{array}{l}\text { Medical } \\
\text { security }\end{array}$ & $\begin{array}{l}\text { Self-reported types of participation in medicare, such as } \\
\text { medical insurance, new rural cooperative medical care, } \\
\text { free medical care, commercial insurance and not } \\
\text { participating }\end{array}$ & 0.0442 \\
\hline
\end{tabular}

Physical examination and laboratory examination refer to the examination items carried out by hospitals or physical examination centers, with or without clinical diagnostic significance as the evaluation criteria.

In the questionnaire survey, we preferred mature and effective measurement tools at home and abroad, which were expressed in bold text. For another part of the index, we used a self-designed questionnaire to describe the specific content of risk assessment.

${ }^{a}$ Alcohol drinking was assessed in four ways: (1) frequency of drinking, (2) alcohol consumed, (3) drinking types and (4) harmful drinking. Harmful drinking refers to the number of days in which men drank more than 5 standard drinking units at a single time in the past 12 months, and women drank more than 4 standard drinking units at a single time.

bSmoking was assessed in three ways: (1) daily smokers report the number of cigarettes smoked every day; other smokers report the average amount of smoking in a week, (2) the age when one started smoking and the age when one started smoking every day and (3) days of exposure to secondhand smoke per week.

\section{Discussion}

Massive health is a global health development concept, focusing on the protection of people's health in an all-round way [1]. Currently, it's difficult for FDs to fully monitor and assess the health status and risk factors of patients with chronic diseases. Additionally, the monitoring indexes and assessment methods used by FDs in different regions for chronic disease management are inconsistent, which makes it difficult to compare, study and evaluate the effects of contracted services on chronic disease management at the national level. Therefore, this study adopted the commonly used Delphi method to construct the HRAIS [14,20,21], aiming to provide standardized assessment tools for chronic diseases and their risk factors. In order to ensure the representativeness of experts' major, 15 experts were selected to optimize the system. The experts were from medical institutions, medical colleges and centers for disease prevention and control. They all have specialized knowledge in their own fields, which contributes to the reliability of the research results. In this study, the expert authority coefficient was more than 0.7 , and the Kendall's W values were between $0.202(p<0.001)$ and $0.210(p<0.001)$, indicating that the degree of concordance between experts was acceptable. That is to say, the HRAIS constructed in this study is reliable and applicable for FDs' health risk assessment.

The HRAIS constructed in this study was based on the concept of massive health. This system can guide FDs to assess the overall health of contracted residents from four dimensions: physiological health, psychosocial health, health-related behaviors and environment [1]. First, of the four first-level indexes, the 
highest weight one was physiological health (42\%), indicating that its importance in monitoring and evaluating health condition was approved by experts in this study. It was also in consistence with the high demand of residents for regular physical examinations in China [22]. In terms of physiological health, the weights of blood pressure (0.0455), blood glucose $(0.0414)$, glycosylated hemoglobin $(0.0272)$ and blood lipids (0.0272) were come out in front. These were the associated factors related to main chronic diseases, reflecting the epidemic trend of high incidence of hypertension, diabetes and cardiovascular diseases in China [23]. In addition, obesity, as a chronic metabolic disease, is a risk factor for many chronic diseases [24, 25]. Body mass index (BMI) is usually used to judge the degree of obesity [26]. Additionally, recent studies have found that the waist circumference was a more relevant risk factor for cardiovascular disease than BMI [24, 25]. Waist circumference was also used by China-PAR risk assessment model as an important index for predicting cardiovascular disease [27]. Moreover, the ratio of waist circumference to hip circumference was an important index in evaluating abdominal obesity. Therefore, BMI, hip and waist circumference were all included in this study. Previously, obesity rate and abdominal obesity rate were used as metabolic indexes for evaluating cardiovascular health of Chinese population [20]. This is in consistence with our study. In short, the HRAIS system is a multi-indexes tool, which included the comprehensive physiological indexes, would facilitate the FDs to perform the risk assessment.

Second, since massive health emphasized the health in an all-round way [1], our system included the psychosocial index used to assess the psychological health and social adaptability. In this study, the weight of psychosocial health $(0.2895)$ ranked the second, just lower than that of physiological health, indicating that experts had a high degree of recognition concerning its importance. In this dimension, the index with the highest weight was cognition (0.0832). Chronic disease was one of the most important risk factors for cognitive impairment in the elderly. The diseases could damage the blood vessels and nervous system, and consequently affected cognitive function [28]. Cognitive impairment often occurred in the elderly with common chronic diseases such as diabetes and hypertension, which might lead to the decline of the quality of life, the aggravation of depressive symptoms, dementia and premature death in the elderly $[29,30]$. In addition, the weights of anxiety and depression were both 0.0511 . Previous studies indicated that anxiety and depression could affect the occurrence, prognosis and development of chronic diseases [31, 32]. Meanwhile, chronic diseases could also lead to depression or anxiety [33]. Thus, it was recommended early screening of depression or anxiety for chronic disease patients. FDs are the initial point of contact for anxiety and depression [34]. In this study, we put forward this dimension, which could help FDs identify the common psychological problems of residents.

Third, this system also focused on health-related behaviors. As is known, the essence of massive health is to encourage people to pursue healthy life, including healthy behaviors and healthy environment [1]. The results showed that the weight of health-related behaviors was 0.2047 . Within this dimension, the weight of alcohol drinking, smoking and medication safety was 0.0397 , ranking the first, followed by activities of daily living (weight 0.0247 ), sleep and rest (weight 0.0247 ), dietary nutrition (weight 0.0182 ) and physical activity (weight 0.0131 ). Positive modification in habits (changes in diet and lifestyle) and treatment adherence are essential for the control of chronic diseases [35]. Previous studies found that 
$80 \%$ of heart disease and type 2 diabetes could be avoided by four interventions: tobacco control, salt reduction, dietary intervention, and increased exercise [36, 37]. Besides, the International Olympic Committee (IOC) consensus meeting pointed out that the prevention and management of chronic diseases required the new programs focuing on physical activity, diet and lifestyle [38]. It was consistent with the massive health and our study design. In addition, the results in this dimension showed that the weight of medication safety was the highest. Medication safety includes a set of indexes to evaluate the drug-use process, including medication types, storage methods, side effects and medication adherence [39]. It is common for residents with chronic diseases to take the long-term medication at home. However, there were some problems, such as poor compliance, the occurrence of adverse drug reactions, improper use of medication and polypharmacy, especially for the elderly [40, 41]. Especially, the poor medication compliance was a global problem, and medication compliance among patients with chronic disease in developed countries was only about $50 \%$ [42]. Thus, to keep medication safety in the residents, it is a daily duty for FDs to encourage and supervise the rational medication.

Fourth, in the dimension of environment, the occupational exposure (weight 0.0260), acoustic environment (weight 0.0260) and indoor air environment (weight 0.0157) were included. Similarly, Freitas et al. [14] also put forward the housing conditions as an important index to assess the health of the European population. The difference was, that they focused on the dampness and water leakage of the living conditions rather than acoustic and indoor air environment. The possible cause was the diversity of study sites and civilization. Besides, medical insurance accounted for the highest weight (0.0442) in the dimension of environment. Bigdeli et al. [43] investigated the medical behaviors of rural patients with diabetes and hypertention in Cambodia. They found that $45 \%$ of patients who came to the hospital to seek treatment had given it up because they could not afford it. In China, the medical insurance system would influence individuals' health care-seeking behaviors [44]. Medical insurance would affect patients' compliance with treatment to a certain extent. Therefore, it is vital for FDs to make optimized treatment plan based on the patients' medical insurance.

\section{Limitation}

This study had three limitations. Firstly, the value of Kendall's W coefficient was not high (0.202-0.210) and it was statistically significant verified by a chi-squared test $(p<0.001)$. It indicated that the degree of concordance between experts was acceptable, and there was still some degree of inconsistent views on different indexes. In the future, we should broaden the study fields from more experts. Secondly, the questionnaires were sent to experts by emails, instead of a face-to-face consultation. Experts may not fully understand the content, although the purpose of the study and the content of the questionnaire were explained in detail, experts may not fully understand the content. Thirdly, all the experts came from Hebei Province in this study. Thus, the HRAIS cannot be generalized in the whole country. So our first step is to apply this system in Hebei Province. In the future, we would recruit more experts from multiple regions in China to gather more comprehensive suggestions. 


\section{Conclusion}

The HRAIS is a comprehensive index system designed for FDs to carry out health risk assessment in the community. The HRAIS contains 38 indexes in 4 dimensions, which can be used to evaluate chronic diseases and their risk factors from physiological health, psychosocial health, health-related behaviors and environment. The HRAIS would help FDs to monitor and assess risk factors associated with chronic diseases, to collect health data in an all-round way, and to implement personalized interventions. It is recommended that HRAIS would be applied to put the massive health into effect and establish the largescale database of chronic diseases and risk factors monitoring.

\section{Abbreviations}

FDs

Family doctors; HRAIS:Health risk assessment index system; SD:Standard deviation; CV:Coefficient of variation; Cr:Experts' authority coefficient; Cs:Familiarity degree coefficient; Ca:Judgment basis coefficient; AHP:Analytical hierarchy process; CR:Random consistency ratio; WHO:World Health Organization; BMI:Body mass index; IOC:International Olympic Committee

\section{Declarations}

\section{Acknowledgements}

We thank all the experts as well as the institutions that have participated in the development of the HRAIS for chronic diseases.

\section{Funding}

Hebei Province Science and Technology Plan Project (17277702D).

Key project of Humanities and Social Sciences Research, Hebei Province (ZD201908).

\section{Availability of data and materials}

Data sharing is not applicable to this article as no datasets were generated or analyzed during the current study.

\section{Author's contributions}


$\mathrm{RH}, \mathrm{MZ}$ analyzed and interpreted the data, and wrote the manuscript. NZ, PZ, RMZ organized experts discussions of this research. JH and HYC designed the research. All authors read and approved the final manuscript.

\section{Ethics approval and consent to participate}

This study was approved by Hebei Medical University.

\section{Consent for publication}

Not applicable.

\section{Competing interests}

The authors declare that they have no competing interests.

\section{Author details}

${ }^{1}$ Department of Clinical Humanistic Care and Nursing Research Center, School of Nursing, Hebei Medical University, Shijiazhuang 050000, Hebei, China;

${ }^{2}$ Department of Science and Technology, Hebei Medical University, Shijiazhuang, Hebei, China

\section{References}

1. Liu DP. The people jointly build and share the "Massive Health". Chinese health. 2016(10):26-7.

2. World Health Organization. 2008-2013 action plan for the global strategy for the prevention and control of noncommunicable diseases: prevent and control cardiovascular diseases, cancers, chronic respiratory diseases and diabetes [J]. 2009. http://www.who.int/nmh/Actionplan-PC-NCD-2008.pdf. Accessed 20 Sept 2010.

3. Kong LZ. China's Medium-to-Long Term Plan for the Prevention and Treatment of Chronic Diseases (2017-2025) under the Healthy China Initiative. Chronic Dis Transl Med. 2017;3(3):135-7.

4. Xu L, Meng Q. The second finding of the Fifth National Health Service Survey-Health Service needs, needs and Utilization. Chinese Journal of Health Information Management. 2014(3).

5. Liu HY, Mu YQ, Feng ZY. Implications of American Managed Care on the Community-based Health Management in China. Medicine and Philosophy (A). 2015;36(9):74-7. 
6. Liu S, Wang L, Zhang T, Liu C, Liang H, Zhang Y, et al. Factors affecting the work competency and stability of family doctors in Shanghai: a tracking study. Bmc Fam Pract. 2019;20(1):95.

7. National Medical Reform Office. Notice on Promoting Guidance for Family Doctor Contract Services. 2016.

http://www.mohrss.gov.cn/SYrlzyhshbzb/shehuibaozhang/zcwj/yiliao/201606/t20160615_241854. Accessed 23 Jul 2019.

8. Fortin M, Chouinard MC, Bouhali T, Dubois MF, Gagnon C, Bélanger M. Evaluating the integration of chronic disease prevention and management services into primary health care. Bmc Health Serv Res. 2013;13:132.

9. Mendis S, Johnston SC, Fan W, Oladapo O, Cameron A, Faramawi MF. Cardiovascular risk management and its impact on hypertension control in primary care in low-resource settings: a cluster-randomized trial. Bull World Health Organ. 2010;88(6):412-9

10. Li ZY. How to solve the problem of signing instead of contract for family doctor service. Rural health in China. 2019;11(13):8-10.

11. LeX. Difficulties and Countermeasures of establishing Health Files in the implementation of Family Doctor contract system. Health Education and Health Promotion. 2013;8(6):476-7.

12. Chen YL, Geng JS, Shi LL, Wei XY, Zhou HL, Cheng Q, et al. Exploration of Family doctor's contract services based on Electronic Health Files. Chinese Journal of Medical Library and Information. 2017;26(5):8-12.

13. McKenna HP. The Delphi technique: a worthwhile research approach for nursing? J Adv Nurs. 1994;19(6):1221-5.

14. Freitas Â, Santana P, Oliveira MD, Almendra R, Bana ECJ, Bana ECC. Indicators for evaluating European population health: a Delphi selection process. Bmc Public Health. 2018;18(1):557.

15. Sun ZQ. Comprehensive evaluation method of medicine and its application [M]. Beijing: Chemical Industry Press; 2006.

16. Mullen PM. Delphi: myths and reality. J Health Organ Manag. 2003;17(1):37-52.

17. Kim M, Jang YC, Lee S. Application of Delphi-AHP methods to select the priorities of WEEE for recycling in a waste management decision-making tool. J Environ Manage. 2013;128:941-8.

18. Karayalcin II. The analytic hierarchy process: Planning, priority setting, resource allocation: Thomas L. SAATY McGraw-Hill, New York, 1980. Eur J Oper Res. 1982;9(1):97-8.

19. Saaty TL. How to make a decision: the analytic hierarchy process. Eur J Oper Res. 1990;48(1):9-26.

20. Jiang Y, Mao F, Li Y, Liu J, Zhang Y, Jiang Y, et al. Construction of China cardiovascular health index. Bmc Public Health. 2018;18(1):937.

21. Turner $S$, Ollerhead E, Cook A. Identifying research priorities for public health research to address health inequalities: use of Delphi-like survey methods. Health Res Policy Syst. 2017;15(1):87.

22. Shang X, Huang Y, Li B, Yang Q, Zhao Y, Wang W, et al. Residents' Awareness of Family Doctor Contract Services, Status of Contract with a Family Doctor, and Contract Service Needs in Zhejiang 
Province, China: A Cross-Sectional Study. Int J Environ Res Public Health. 2019;16(18).

23. Zeng XY, Li YC, Liu SW, Wang LJ, Liu YN, Liu JM, et al. Subnational analysis of probability of premature mortality caused by four main non-communicable diseases in China during 1990-2015 and " Health China 2030" reduction target. Zhonghua Yu Fang Yi Xue Za Zhi. 2017;51(3):209-14.

24. Janssen I, Katzmarzyk PT, Ross R. Waist circumference and not body mass index explains obesityrelated health risk. Am J Clin Nutr. 2004;79(3):379-84.

25. Karaca Ü, Schram MT, Houben AJ, Muris DM, Stehouwer CD. Microvascular dysfunction as a link between obesity, insulin resistance and hypertension. Diabetes Res Clin Pr. 2014;103(3).

26. Feng RN, Zhao C, Wang C, Niu YC, Li K, Guo FC, et al. BMI is strongly associated with hypertension, and waist circumference is strongly associated with type 2 diabetes and dyslipidemia, in northern Chinese adults. J Epidemiol. 2012;22(4):317-23.

27. Yang X, Li J, Hu D, Chen J, Li Y, Huang J, et al. Predicting the 10-Year Risks of Atherosclerotic Cardiovascular Disease in Chinese Population: The China-PAR Project (Prediction for ASCVD Risk in China). Circulation. 2016;134(19):1430-40.

28. Su X, Shang L, Xu Q, Li N, Chen J, Zhang L, et al. Prevalence and predictors of mild cognitive impairment in Xi'an: a community-based study among the elders. Plos One. 2014;9(1):e83217.

29. Park B, Park J, Jun JK. Cognitive impairment, depression, comorbidity of the two and associated factors among the early sixties in a rural Korean community. Plos One. 2013;8(11):e79460.

30. Lyu J, Burr JA. Socioeconomic Status Across the Life Course and Cognitive Function Among Older Adults: An Examination of the Latency, Pathways, and Accumulation Hypotheses. J Aging Health. 2016;28(1):40-67.

31. Pumar MI, Gray CR, Walsh JR, Yang IA, Rolls TA, Ward DL. Anxiety and depression-Important psychological comorbidities of COPD. J Thorac Dis. 2014;6(11):1615-31.

32. Liu RH, Pan JQ, Tang XE, Li B, Liu SF, Ma WL. The role of immune abnormality in depression and cardiovascular disease. J Geriatr Cardiol. 2017;14(11):703-10.

33. DeJean D, Giacomini M, Vanstone M, Brundisini F. Patient experiences of depression and anxiety with chronic disease: a systematic review and qualitative meta-synthesis. Ont Health Technol Assess Ser. 2013;13(16):1-33.

34. Craven MA, Bland R. Depression in primary care: current and future challenges. Can J Psychiatry. 2013;58(8):442-8.

35. Pisano González MM, González Pisano A. Modifying habits and treatment adherence, essential for controlling the chronic disease. Enferm Clin. 2014;24(1):59-66.

36. Asaria P, Chisholm D, Mathers C, Ezzati M, Beaglehole R. Chronic disease prevention: health effects and financial costs of strategies to reduce salt intake and control tobacco use. Lancet. 2007;370(9604):2044-53.

37. Beaglehole R, Bonita R, Horton R, Adams C, Alleyne G, Asaria P, et al. Priority actions for the noncommunicable disease crisis. Lancet. 2011;377(9775):1438-47. 
38. Matheson GO, Klügl M, Engebretsen L, Bendiksen F, Blair SN, Börjesson M, et al. Prevention and management of non-communicable disease: the IOC consensus statement, Lausanne 2013. Sports Med. 2013;43(11):1075-88.

39. Ascione FJ, Kirscht JP, Shimp LA. An assessment of different components of patient medication knowledge. Med Care. 1986;24(11):1018-28.

40. Liang CB, Zhong SE, Wang ZT. Analysis on the current situation and influencing factors of safe Drug use in the families of residents in a Town of Dongguan City. Journal of Nursing. 2013;20(3):28-31.

41. Chan FW, Wong FY, So WY, Kung K, Wong CK. How much do elders with chronic conditions know about their medications? Bmc Geriatr. 2013;13:59.

42. Burkhart PV, Sabaté E. Adherence to long-term therapies: evidence for action. J Nurs Scholarsh. 2003;35(3):207.

43. Bigdeli M, Jacobs B, Men CR, Nilsen K, Van Damme W, Dujardin B. Access to Treatment for Diabetes and Hypertension in Rural Cambodia: Performance of Existing Social Health Protection Schemes. Plos One. 2016;11(1):e146147.

44. Jin Y, Yuan B, Zhu W, Zhang Y, Xu L, Meng Q. The interaction effect of health insurance reimbursement and health workforce on health care-seeking behaviour in China. Int $\mathrm{J}$ Health plann and manage. 2019;34(3):900-11.

\section{Figures}




\section{Literature review}

-Domestic and international published reports and articles

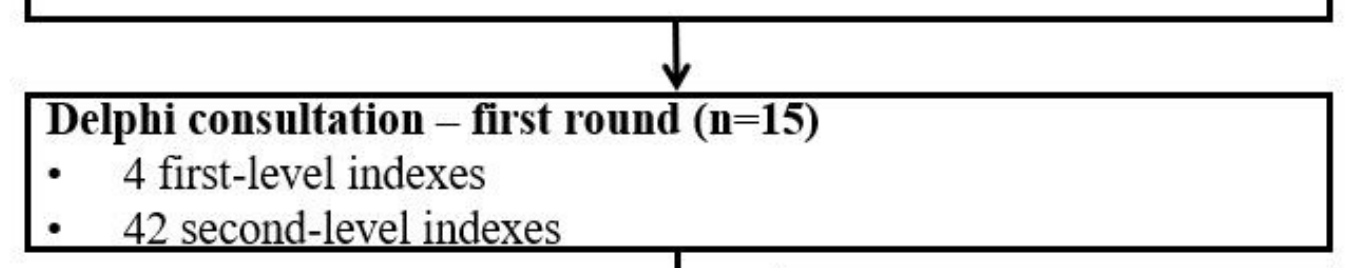

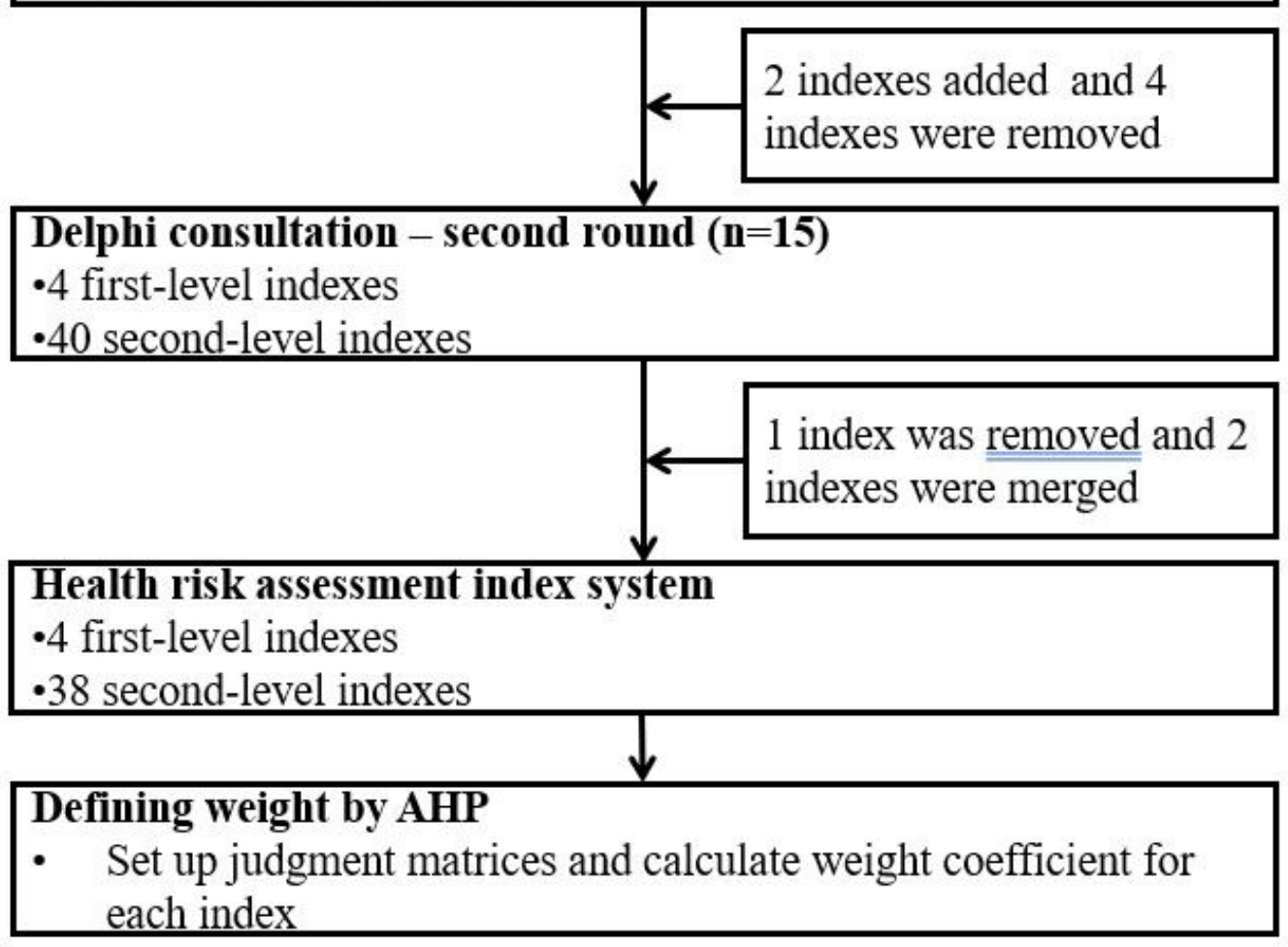

Fig.1 The flowchart of study process

Figure 1

The flowchart of study process 